\title{
IMPAIRMENTS IN ORIENTING TO VISUAL STIMULI IN MONKEYS FOLLOWING UNILATERAL LESIONS OF THE SUPERIOR SULCAL POLYSENSORY CORTEX
}

\author{
Karen E. Luh*, Charles M. Butter*† and Henry A. Buchtel $\$$ \\ *Neuroscience Laboratory and Department of Psychology, The University of Michigan, Ann Arbor, MI 48109, \\ U.S.A. and $\ddagger$ Departments of Psychology and Psychiatry, Psychology Services, Veterans’ Administration \\ Hospital, Ann Arbor, MI 48105, U.S.A. \\ (Accepted 17 December 1985)
}

\begin{abstract}
Monkeys were tested for head and eye orientation to illuminated lamps in a hemisphere before and after serial, unilateral lesions of the polysensory superior temporal cortex (STS) or control lesions. Following SIS lesions they were impaired in orienting to contralateral lamps; this impairment was more severe and persistent when a ipsilateral stimulus in the mirror-image position was simultaneously presented. These findings, together with deficits in manual reaching and grasping observed following STS lesions, support the view that the STS is part of a polysensory system controlling attention and exploratory movements.
\end{abstract}

\section{INTRODUCTION}

Contralateral neglect has been reported in monkeys after unilateral ablation of the posterior parietal cortex $[7,17,19,26]$, frontal eye fields $[16,30,35,36,55,64]$, cingulate cortex [63] and a region within area 6 [50]. As pointed out by one of us in a recent review [13], these cortical areas all receive projections from several thalamic nuclei, including parts of the dorsomedial nucleus (pars multiformis) and the paralamellar portion and the medial pulvinar $[4,6,10,29,31,40,58,59]$, which are targets of the deeper layers of the superior colliculus [25]. In addition, these cortical areas are directly interconnected $[4,15,22,23,28$, $32,33,40,42,43,45,46,49,58]$ and project back to the same collicular layers that provide input to their thalamic projection nuclei [21, 33, 34, 37, 47]. Moreover, unilateral lesions of the superior colliculus that include these deeper layers also lead to contralateral neglect in monkeys $[1,17,55]$. With regard to their physiological features, unit recordings in these cortical areas disclose significant numbers of polysensory neurons [9, 27, 38, 39, 51-54].

If these functional and morphological characteristics are critical features of cortical areas controlling spatially directed attention, then one would expect that another area of cortex with these same characteristics - the dorsal bank and depths of the superior temporal sulcus (STS)-also participates in spatially directed attention. The STS receives projections from the medial pulvinar [12]; it is directly interconnected with the above-described cortical areas involved in spatial attention $[2,4,6,22,28,33,43,44,46,56,57]$ and, like them, projects to the deeper tectal layers [21]. Furthermore, a large proportion of STS neurons are polysensory $[8,11,18]$.

In order to test the prediction that the STS, like other cortical areas with similar anatomical and physiological features, controls spatially directed attention, we investigated

†Address correspondence to: Charles M. Butter. Neuroscience Laboratory, 1103E Huron St, Ann Arbor, MI 48104-1687, U.S.A. 
orientation to single and bilaterally presented visual stimuli in monkeys before and after unilateral STS lesions. We also observed the effects of these lesions on manual reaching and on responses to auditory, tactile and visual stimuli outside the testing apparatus.

\section{METHODS}

Three male cynomolgus monkeys (Macaca fascicularis) were trained to orient to illuminated lamps on the inner surface of a hemisphere, $76 \mathrm{~cm}$ in diameter. Eight of the lamps (G.E. 1819) were arrayed horizontally, 15, 30,45 and $60^{\circ}$ to the left and right of center; the remaining lamps were arrayed vertically, $15^{\circ}, 30^{\circ}$ and $45^{\circ}$ above and below the center. A hole, $1.5 \mathrm{~cm}$ in diameter, was located below each lamp. A $3-\mathrm{cm}$ diameter hole in the center of the hemisphere was used to videotape or observe the monkeys. During training and test sessions, each approximately $30 \mathrm{~min}$ in duration, the monkeys sat in a primate chair.

In the initial preoperative training sessions, the monkeys learned to fixate the center hole in the hemisphere when the experimenter, standing behind the hemisphere, tapped the edge of the central hole. If the monkey continued to fixate the central hole for $1-3 \mathrm{sec}$, then on 28 trials a single lamp was illuminated. If the monkey orientated its head and eyes toward the lamp within approximately $1 \mathrm{sec}$ after it was illuminated, a small piece of fruit was presented to it through the hole below the lamp, which was then extinguished. If the monkey oriented elsewhere before fixating the illuminated lamp or failed to orient during the first second of the lamp's illumination, the lamp was extinguished and no reward was given. Each lamp was singly illuminated twice in each session. On an additional 16 trials, two lamps in the horizontal array, equidistant from the center, were illuminated. If the animal oriented to either lamp, it was presented with food through the hole under one of the two lamps, the location of which was randomized. The monkeys were rewarded equally often on each side in bilateral-stimulus trials in order to discourage them from orienting consistently to one side. In all other respects, the procedures were the same as those used on single stimulus trials. $\Lambda 1$ the stimuli were presented in a pseudorandom order. After the monkeys learned to fixate the center of the hemisphere and orient to illuminated lamps, they were tested in this situation 3-5 times/week for 4-8 weeks. M1 and M2 were videotaped on several sessions both before and after surgery; analysis of the tapes revealed that the experimenter's judgement of their orienting responses was accurate.

Following the completion of preoperative testing, two monkeys (M1 and M2) received a unilateral STS lesion (M1 on the right side, $M 2$ on the left side); the third (C1) received a unilateral lesion of the prefrontal cortex anterior to the frontal eye fields. Within 2-5 days after the first operation, they were retested in the hemisphere for 7-10 weeks. One to two days following the completion of testing, the three monkeys received a second operation in which the STS in the hemisphere opposite the first lesion was ablated. They were then retested in the hemisphere for 10 weeks, beginning 2-7 days following surgery. Postoperative testing followed the same procedures used preoperatively. Following each operation, the monkeys were observed reaching for and grasping food and reacting to visual, auditory and tactile stimuli.

The general surgical procedures employed are decribed elsewhere [14]. The cortical removals were made with a small-gauge sucker under an operating microscope through openings rongcured in the skull. The STS lesions were intended to remove the cortex in the dorsal bank and fundus as well as in the anterior half of the ventral bank of the sulcus (area TEa), which, like the dorsal bank and fundus, receives an input from the inferior parietal cortex [56].

Following the completion of testing, the monkeys were sacrificed and their brains were prepared for histological examination by methods previously described [14]. Examination of thionine-stained cross-sections disclosed that removals of the targeted sulcal region varied from near-total (M1 right, $\mathrm{M} 2$ right, $\mathrm{C} 1$ left) to extensive in the other two hemispheres (M1 left and M2 left), in which anterior portions of this area were largely spared (see Fig. 1). The lesions also included other cortical areas, probably as a result of post-surgical infarcts which often occur following brain surgery in this species [41]. Slight damage to the superior temporal gyrus, inferior parietal cortex and inferior temporal cortex was found in all cases. Area MT, a visual area in the ventral bank of the STS, whose position was estimated by anatomical landmarks $[60,62]$, was missing in two hemispheres ( $\mathrm{Cl}$, left side; M2, left side), severely damaged in two others (M1, left; M2 right) and slightly damaged in one (M1, right). C1's control lesion involved the cortex on the dorsolateral surface of the frontal lobe, including the anterior two-thirds of the sulcus principalis, and spared the frontal eye fields posteriorly (see Fig. 1). Damage to the underlying white matter was minimal in all cases. Examination of the lateral geniculate nuclei disclosed that they were intact with no signs of cell loss in $\mathrm{M} 2$ ond $\mathrm{Cl}$ (see Fig. 2); the lateral geniculate on the right side in M1 showed slight cell loss in the medial sector, but the left lateral geniculate was intact.

\section{RESULTS}

Following the first unilateral STS lesion, M1 was hyporesponsive for several days and M2 for several weeks to contralateral tactile stimuli and visual stimuli. M1 also showed contralateral auditory neglect briefly following surgery. Whereas none of the monkeys showed hand preferences before surgery, for several weeks following surgery both M1 and 

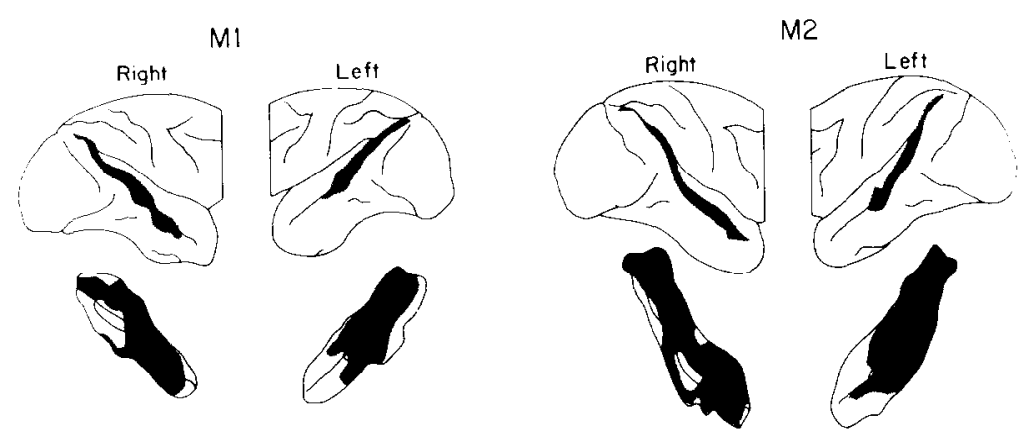

C1
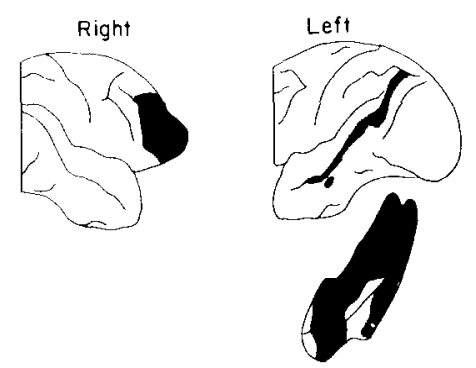

Fig. 1. Reconstructions of the STS and frontal lesions. Cortical removals indicated by stippling. Below each lateral view of the hemisphere with STS lesions is a reconstruction of the STS opened to display areas removed in the upper and lower banks and fundus. The small black area in the left hemisphere of $\mathrm{C} 1$ indicates a superficial cortical lesion.

M2 strongly favored the ipsilateral hand in reaching for objects. They also reached inaccurately for food and grasped it awkwardly with the contralateral hand for several days (M1) or several weeks (M2) following surgery. Both monkeys, however, used their limbs normally in walking and climbing. $\mathrm{C} 1$ showed no disturbance in its reactions following frontal surgery.

In formal testing following the first operation, M1 and M2's orienting reactions to the horizontally arrayed lamps changed markedly. During the first 2 weeks of postoperative testing, both monkeys frequently failed to respond to singly illuminated lamps contralateral to their lesions; after 5 weeks of testing they returned to preoperative levels of responding to contralateral lamps (see Fig. 3A). These deficits, as well as all others reported below, did not vary with the eccentricity of the stimuli. In contrast, M1 and M2's responses to lamps ipsilateral to their lesions were unchanged following surgery, except for a transient impairment in M1 during the first 4 sessions. As shown in Fig. 3B, M1 and M2 showed more striking and longer lasting changes in orienting responses on bilateral than on singlestimulus trials; they showed a strong bias to respond to the ipsilateral member of paired lights throughout postoperative testing. $\mathbf{M} 1$ and $\mathbf{M} 2$ also showed slight impairments in responding to lamps in the vertical array in the first 4-5 weeks following the first operation (see Fig. 3C). Cl showed no changes in its test performance or in reactions to stimuli outside the testing situation following frontal surgery. Following unilateral STS removal in its second operation, $\mathrm{C} 1$ showed impairments similar to those of $\mathrm{M} 1$ and $\mathrm{M} 2$ after their first STS lesions (see Fig. 3), including transient visual and auditory neglect outside the testing situation. 
Following their second STS lesions, M1 and M2 showed more severe and longer lasting contralateral neglect in all three modes than they did after the first STS lesion. Similarly, their preference for the ipsilateral hand and clumsiness in grasping food with the hand contralateral to the second lesion was more obvious than were their comparable impairments after the first operation. Moreover, for several weeks after the second STS removal, M1 and M2 both made more errors in reaching for food with the ipsilateral hand than they had made soon before the second operation, although these crrors were not as pronounced as those performed with the contralateral hand.

Following their second STS lesion, M1 and M2 were impaired for several weeks in orienting to single contralateral lamps (see Fig. 3A). Whereas M1's performance with single contralateral lamps steadily improved over the 10 -week course of testing following its second operation, M2's performance appeared to first improve and then deteriorate after the first 4 weeks of testing. To determine whether these changes in M2's performance were statistically reliable, the binomial probability test was used to compare its performance with single contralateral lamps in each of the 10 weeks following the second operation with its performance with the same lamps prior to the first operation. Since 10 statistical tests were made, the confidence level of each one was set at 0.005 . The results of these tests disclosed that compared to its preoperative performance, M1's performance was significantly impaired in the first three weeks of testing ( $P=0.0000$ for all three comparisons) and in the last six weeks of testing (week 5: $P=0.0012$; week 6: $P=0.0016$; weeks 7-10: $P=0.0000$ in each case), but its performance was not significantly impaired in week $4(P=0.6564)$. Thus, it appears that the deterioration in M1's performance after the fourth week of testing was indeed a real one. Furthermore, M1's errors in tests conducted after the fourth week, like its errors in the first 3 weeks following the second operation, were predominantly due to maintenance of fixation of the central hole in the hemisphere. M1 showed no signs of sickness or lethargy during the period in which its performance deteriorated; we are unable to account for its occurrence.

Both monkeys were also impaired in orienting to lamps ipsilateral to the second lesion during the first few weeks of testing, although to a lesser extent than they were in orienting to contralateral lamps. As shown in Fig. 3B, on bilateral stimulus trials following the second operation, M1 and M2 were strongly biased toward the lamps ipsilateral to the second lesion; this bias, like the one seen following the first operation, declined somewhat over the course of testing.

In contrast to their good performance in orienting to lamps in the vertical array following the first operation, M1 and M2's deficits in orienting to these lamps following the second operation were as severe and long lasting as were their deficits in orienting to the horizontally arrayed lamps during the same tests (see Fig. 3C).

\section{DISCUSSION}

It is unlikely that damage to the inferior parietal cortex or to the inferior temporal cortex (area TE) on the surface of the temporal lobe could account for the deficits reported here, for damage to these areas was minor in all cases. The extent to which the TE cortex in the ventral bank of the STS was removed was not related to the degree of impaired orientation to singly illuminated lamps, the measure showing the greatest variation between animals $(17-40 \%$ loss, relative to preoperative performance levels). Lesions of the superior temporal gyrus, which were more variable than those of the aforementioned cortical areas, were also unrelated to severity of the deficits. Furthermore, lesions restricted to the rostral portion of 

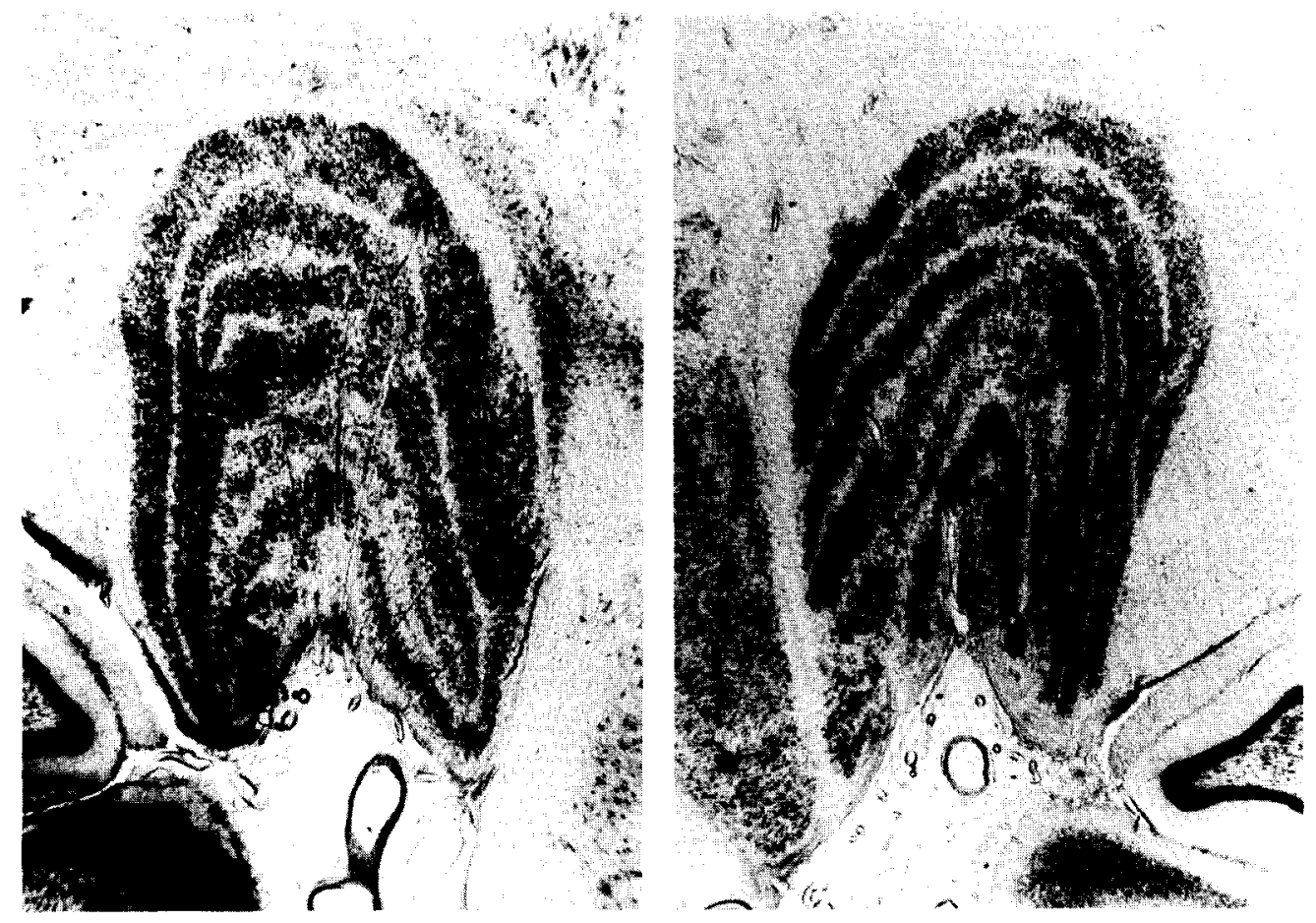

FIG. 2. Photomicrograph of a thionine-stained section through the lateral geniculate nuclei of M2. 


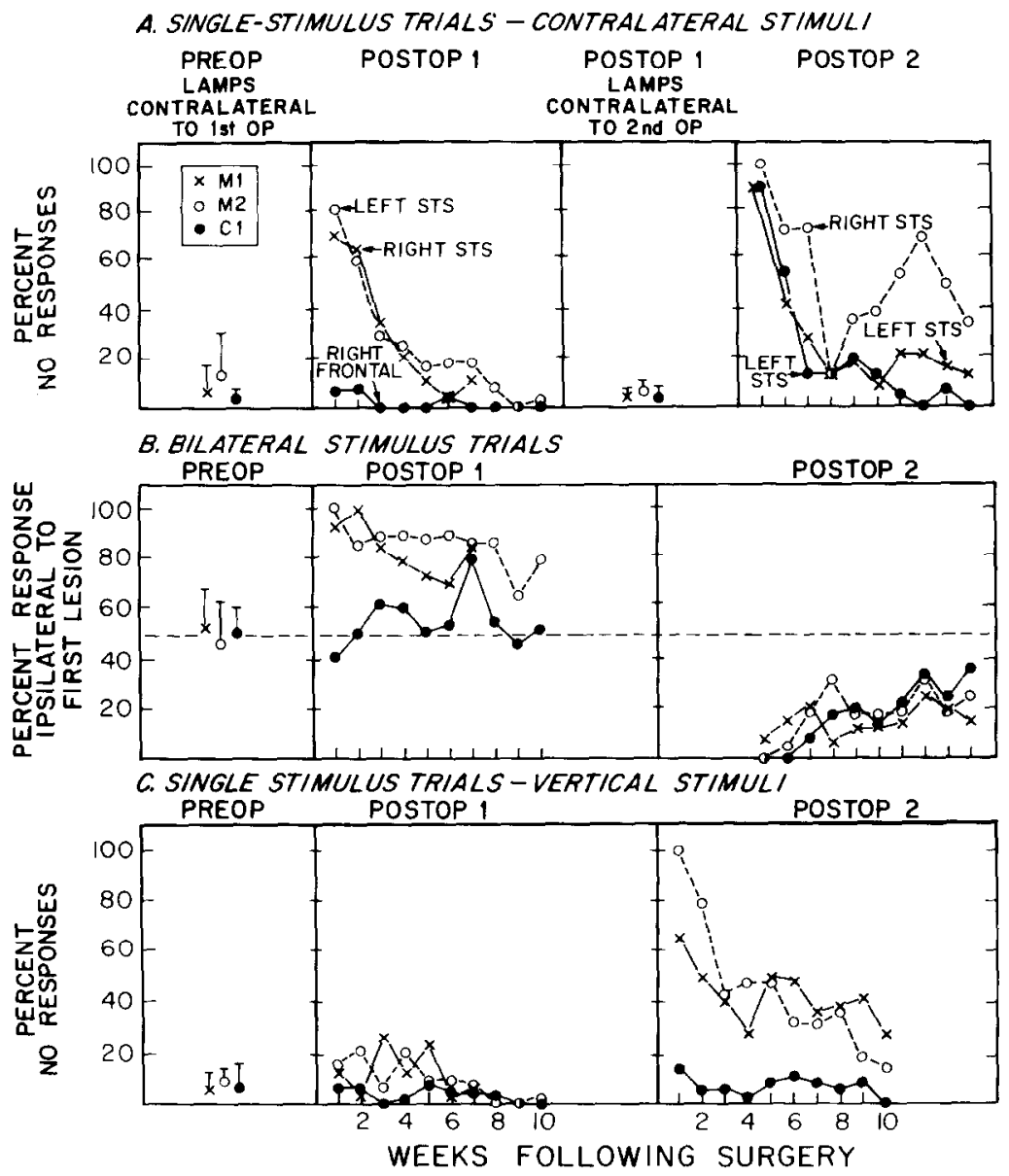

FIG. 3. (A) Percent trials on which subjects failed to orient initially to lamps in horizontal array contralateral to lesion on single stimulus trials. Percent response failures to lamps contralateral to second operation (third panel) based on performance in last 4 weeks of testing following first operation. (B) Percent trials on which subjects failed to orient initially to lamps in horizontal array contralateral to lesion on bilateral stimulus trials. (C) Percent trials on which subjects failed to orient initially to lamps in vertical array.

this gyrus do not lead to neglect [61]. With regard to area MT, lesions involving its total removal (C1 left and $\mathrm{M} 2$ left) resulted in impairments ranking fifth and third, respectively; following the lesion with the most sparing of MT (M1, right side), the resulting impairment ranked second out of five. These findings suggest that MT damage by itself cannot entirely account for the visual deficits we found, although it might have contributed to them, as well as to deficits in manually grasping food [5]. This interpretation is consistent with the finding that selective unilateral lesions of the caudal third of the STS ventral bank the region in which MT is located) do not lead to contralateral neglect in monkeys [61].

On the basis of the above analyses, then, it appears that the critical lesion involved all or some part of the STS rather than adjacent structures. The extent to which the anterior third of the STS was ablated may have been a crucial factor in the severity of the neglect. M2 
showed the most severe deficit following its right STS lesion that included the most extensive removal of this portion of the STS; conversely, M1 showed the least deficit following its left STS lesion sparing this region. On the other hand, lesions restricted to this portion of the STS and the adjoining superior temporal gyrus fail to produce neglect [61].

The movement deficits we observed, as well as auditory and tactile neglect, were more severe and persistent after the second STS lesions than after the first. Furthermore, only after the second STS lesion did M1 and M2 show (a) deficits in responding to ipsilateral as well as to contralateral stimuli, an observation consistent with the report that one-stage, bilateral STS lesions result in a transient, multimodal neglect of stimuli [48], (b) reaching disorders with the ipsilateral as well as contralateral hand, and (c) impaired orientation to lamps on the vertical meridian. These findings suggest that following the removal of STS cortex in one hemisphere, the remaining STS cortex in the contralateral hemisphere took over some of its functions.

The monkey's strong bias to respond to the ipsilateral lamp on bilateral stimulus trials, even after their deficits in orienting on single-stimulus trials had decreased or disappeared, suggests that their orienting deficits were due to attentional impairments rather than sensory disturbances. Furthermore, impairments in manual reaching and grasping similar to those reported here also have been observed in monkeys with neglect following unilateral removal of other cortical areas $[20,24,30,50]$. The present findings, then, strengthen the view that attentional and exploratory motor mechanisms are closely linked $[13,50]$.

Acknowledgements- This research was supported by an NIMH research grant (MH 26489) and by an NSF Graduate Fellowship to K.E. Luh.

\section{REFERENCES}

1. Albano, J. E., Mishkin, M., Westbrook, L. E. and Wurtz, R. H. Visuomotor deficits following ablation of monkey superior colliculus. J. Neurophysiol. 48, $338 \cdot 351,1982$.

2. Anderson, R. A., Asanuma, C. and Cowan, W. M. Observations on the callosal and associational corticocortical connections of area $7 \mathrm{~A}$ of the macaque monkey. Neurosci. Abstr. 8, 1982.

3. Baleyidier, C. and Mauguiere, F. Pulvinar-lateroposterior afferents to cortical area 7 in monkeys demonstrated by horseradish peroxidase tracing technique. Exp. Brain Res. 27, 501 507, 1977.

4. BaLeyoier, C. and MaLquiere, F. The duality of the cingulate gyrus in monkey. Neuroanatomical study and functions hypothesis. Brain 103, 525-554, 1980.

5. Barber, G., Gattass, R. and Gross, C. G. Unpublished data in: Gross, C. G., Bruce, C. J. and Desimone, R. Cortical visual areas of the temporal lobe: three areas in the macaque. In Cortical Sensory Organization, Vol. 2 , Multiple Visual Areas. C. N. WoolseY (Editor).Humana Press, Clifton, N. J., 1981.

6. BaRbas, H. and Mesulam, M.-M. Organization of afferent input to subdivisions of area 8 in the rhesus monkey. J. comp. Neurol. 200, 407 431, 1981.

7. Bates, J. A. V. and Ettlingle, G. Posterior biparietal ablations in the monkey. AMA.Arch. Neurol. 3,177 192, 1960.

8. Benevento, L. A., Fallon, J. H., Davis, B. and Rezak, M. Auditory visual interaction in single cells in the cortex of the superior temporal sulcus and the orbital frontal cortex of the macaque monkey. Exp. Neurol. 57 , $849-872,1977$.

9. Bignall, K. E. and Imbert, M. Polysensory and corticocortical projections to frontal lobe of squirrel and rhesus monkey. Electroencephal. Clin. Neurophysiol. 26, 206 215, 1969.

10. Bos, J. and Benfevento, L. A. Projections of the medial pulvinar to orbital cortex and frontal eye fields of the rhesus monkey (Macaca mulatta). Exp. Neurol. 49, 487-496, 1975.

11. Bruce, C., Dfsimone, R. and Gross, C. G. Visual properties of neurons in a polysensory area in superior temporal sulcus of the macaque. $J$. Neurophysiol. 46, 369 384, 1981.

12. Burton, H. and Jones, E. G. The posterior thalamic region and its cortical projection in New World and Old World monkeys. J. comp. Neurol. 168, 249-301, 1976.

13. Butrer, C. M. The role of polysensory neuronal structures in spatially-directed attention and orienting responses to cxternal stimuli. In Attention: Theory, Brain Function and Clinical Applications. D. SHEER and K. Pribram (Editors). Academic Press, New York (in press). 
14. Campbell, A. L., Butter, C. M. and Leiby, C. C. Effects of inferior temporal lesions on visual discrimination performance in monkeys with complete and incomplete striate cortex ablations. Behavioral Neuroscience $\mathbf{9 8 ,}$ 935-945, 1984.

15. Chavis, D. A. and Pandya, D. N. Further observations on corticofrontal connections in the rhesus monkey. Brain Res. 117, 369-386, 1976.

16. Chowne, D. P., Yeo, C. H. and Russell, I. The effects of unilateral frontal eye field lesions in the monkey: visuomotor guidance and avoidance behaviour. Behav. Brain Res. 2, 165-188, 1981.

17. Denny-Brown, D. and Chambers, R. A. The parietal lobe and behaviour. Proc. Assoc. Res. Nerv. Ment. Dis. 36, 35117,1958 .

18. Desimone, R., Bruce, C. J. and Gross, C. G. Neurons in the superior temporal sulcus of the macaque still respond to visual stimuli after removal of striate cortex. Soc. Neurosci. 5, 781, 1979.

19. EIDELberG, E. and Srhwart7., A. S. Experimental analysis of the extinction phenomenon in monkeys. Brain 94, 91-108, 1971 .

20. Faugier-Grimaud, S., Frenois, C. and Stein, D. G. Effects of posterior parietal lesions on visually guided behavior in monkeys. Neuropsychologia 16, 151-168, 1978.

21. FrIES, W. Cortical projections to the superior colliculus in the macaque monkey: a retrograde study using horseradish peroxidase. J. comp. Neurol. 230, 55-76, 1984.

22. Godschalk, M., Lemon, R. N., Kuypers, H. G. and Ronday, K. H. Cortical afferents and efferents of monkey postarcuate area: an anatomical and electrophysiological study. Exp. Brain Res. 56, 410-424, 1984.

23. Goldman, P. S. and Nauta, W. J. H. Columnar distribution of cortico-cortical fibers in the frontal association, limbic and motor cortex of the developing rhesus monkey. Brain Res. 122, 393-413, 1977.

24. HAAXMA, R. and KUYPERS, H. G. J. M. Intrahemispheric cortical connections and visual guidance of hand and finger movements in the the rhesus monkey. Brain 98, 239-260, 1975.

25. Harting, J. K., Huerta, M. F., Frankfurter, A. J., Strominger, N. L. and Royce, G. J. Ascending pathways from the monkey superior colliculus: an autoradiographic analysis. $J$. comp. Neurol. 192, 853-882, 1980.

26. Heilman, K. M., Pandya, D. H. and Geschwind, N. Trimodal inattention following parietal lobe ablations. Trans. Amer. Neurol. Assoc 95, 250-261, 1970.

27. Hyvarinen, J. and Poranen, A. Function of parietal association area 7 as revealed from cellular discharges in alert monkeys. Brain 97, 673-692, 1974.

28. Jones, E. G. and Powell, T. P. S. An anatomical study of converging sensory pathways within the cerebral cortex of the monkey. Brain 93, 793-820, 1970.

29. KADSON, D. L. and JACOBSON, S. The thalamic afferents to the inferior parietal lobule in the rhesus monkey. $J$. comp. Neurol. 177, 685-706, 1978.

30. Kennard, M. A. Alterations in response to visual stimuli following lesions of frontal lobe in monkey. Arch. Neurol. Psychiat. 41, 1153-1165, 1939.

31. KIEVIT, J. and KUYPERS, H. G. J. M. Organization of the thalamo-cortical connections to the frontal lobe in the rhesus monkey. Exp. Brain Res. 29, 299-322, 1977.

32. KUNZLE, H. An autoradiographic analysis of the efferent connections from premotor and adjacent prefrontal regions (areas 6 and 9) in Macaca fascicularis. Brain, Behav, Evol. 15, 185-234, 1978.

33. Kunzle, H. and Akert, K. Efferent connections of cortical area 8 (frontal eye field) in Macaca fascicularis. A reinvestigation using the autoradiographic techniques. $J$. comp. Neurol. 173, 147-164, 1977.

34. Kuypers, H. G. J. M. and Lawrence, D. G. Cortical projections to the red nucleus and the brain stem in the rhesus monkey. Brain Res. 4, 151-188, 1967.

35. Latro, R. and Cowey, A. Visual field defects after frontal eye field lesions in monkeys. Brain Res. 30, 1-24, $1971 \mathrm{a}$.

36. Latro, R. and Cowey, A. Fixation changes after frontal eye field lesions in monkey. Brain Res. 30, 25-36, $1971 \mathrm{~b}$.

37. Leichnet L, G. R., Spencer, R. F., Hakdy, S. G. P. and Astruc. J. The prefrontal corticotectal projection in the monkey: an anterograde and retrograde horseradish peroxidase study. Neurosci. 6, 1023-1041, 1981.

38. Leinonen, L., Hyvarinen, J., Nyman, G. and Linnankowski, I. Functional properties of neurons in lateral part of associative area 7 in awake money. Exp. Brain Res. 34, 299 320,1979.

39. Leinonen, L. and Nyman, G. II. Functional properties of cells in anterolateral part of area 7 associative face area of awake monkeys, Exp. Brain Res. 34, 321-333, 1979.

40. Mesulam, M.-M., van Hoesen, G. W., Pandya. D. N. and Geschwind, N. Limbic and sensory connections of the inferior parietal lobule (area PG) in the rhesus monkey: a study with a new method for horseradish peroxidase neurochemistry. Brain Res. 136, 393-414, 1977.

41. Murray, E. A. and Mishkin, M. Severe tactual as well as visual memory deficits follow combined removal of the amygdala and hippocampus in monkeys. $J$. Neurosci. 4, 2565-2580, 1984.

42. Pandya, D. N., Domesick, V. B., van Hoesen, G. W. and Mesulam, M. Projections of the cingulate gyrus and cingulum in the rhesus monkey. Anat. Rec.172, 379, 1972.

43. Panuya, D. N. and Kuypers, H. G. J. M. Cortico-cortical connections in the rhesus monkey. Brain Res. 13, 13-36, 1969. 
44. Pandya, D. N. and Seltzer, B. Intrinsic connections and architectonics of posterior parietal cortex in the rhesus monkey. J. comp. Neurol. 204, 196-210,1982.

45. Pandya, D. N. and VIgnolo, L. A. Intra- and interhemispheric projections of the precentral, premotor and arcuate areas in the rhesus monkey. Brain Res. 26, 217-223, 1971.

46. Pandya, D. N., van Hoesen, G. W. and Mesulam, M.-M. Efferent connections of the cingulate gyrus in the rhesus monkey. Exp. Brain Res. 42, 319-330, 1981.

47. Petras, J. M. Connections of the parietal lobe. J. Psychiat. Res. 8, 189 201, 1971.

48. Petrides, M. and IVERSEN, S. D. Restricted posterior parietal lesions in the rhesus monkey and performance on visuospatial tasks. Brain Res. 161, 63-77, 1979.

49. Petrides, M. and Pandya, D. N. Projections to the frontal cortex from the posterior parietal region in the rhesus monkey. J. comp. Neurol. 288, 105-116, 1984.

50. Rizzolatti, G., Matelli, M. and Pavesi, G. Deficits in attention and movement following the removal of postarcuate (area 6) and pre-arcuate (area 8) cortex in macaque monkeys. Brain 106, 655-673, 1983.

51. Rizzolatt1, G., Scandolara, C., Matelli, M. and Gentilucci, M. Afferent properties of the peri-arcuate neurons in macaque monkeys. I. Somato-sensory responses. Behav. Brain. Res. 2, 125-146, 1981a.

52. Rizzolatt, G., Scandolara, C., Matelli, M. and Gentiluccl, M. Afferent properties of the peri-arcuate neurons in macaque monkeys. II. Visual responses. Behav. Brain Res. 2, 147-163, $1981 \mathrm{~b}$.

53. Robinson, D. L., Goldberg, M. E. and Stanton, G. B. Parietal association cortex in the primate: sensory mechanisms and behavioral modulations. J. Neurophysiol. 41, 896-909, 1978.

54. SChechter, P. B. and MurPhy, E. H. Response characteristics of single cells in squirrel monkey frontal cortex. Brain Res. 96, 66-70, 1975.

55. Schlller, P. H., Tkue, S. D. and Cunway, J. L. Deficits in eye movements following frontal eye field and superior collicular ablations. J. Neurophysiol. 44, 1175-1189, 1980.

56. Seltzer, B. and PANDYA, D. N. Afferent cortical connections and architectonics of the superior temporal sulcus and surrounding cortex in the rhesus monkey. Brain Res. 149, 1 24, 1978

57. Seltzer, B. and Pandya, D. N. Further observations on parieto-temporal connections in the rhesus monkey. Exp. Brain Res. 55, 301-312, 1984.

58. Stanton, G. B., Cruce, W. L. R., Goldberg, M. E. and Robinson, D. L. Some ipsilateral projections to areas $\mathrm{PF}$ and $\mathrm{PG}$ of the inferior parjetal lobule in monkeys. Neurosci. Letters 6, 243-250, 1977.

59. Trojanowski, J. Q. and JaCobson, S. Medial pulvinar afferents to frontal eye fields in rhesus monkeys demonstrated by horseradish peroxidase. Brain Res. 80, 395-411, 1974.

60. UNGERLEIDER, L. G. and Mishkin, M. The striate projection zone in the superior temporal sulcus of $M a c a c a$ mulatta: location and topographic organization. J. comp. Neurol. 188, 347 366, 1979.

61. Valenstein, E., Heilman, K. M., Watson, R. T. and van den Abell, T. Nonsensory neglect from parietotemporal lesions in monkeys. Neurol. 32, 1198-1201, 1982.

62. Van Essen, D. C., Maunsell, J.H.R. and Bixby, J. L. The middle temporal visual area in the macaque: myeloarchitecture, connections, functional properties and topographic organization. J. comp. Neurol. 199, 293- 326, 1981.

63. Watson, R. T., Heilman, K. M., Cauthen, J. C. and King, F. A. Neglect after cingulectomy. Neurol. 23, $1003-1007,1973$.

64. Welch, K. and Stuteville, P. Experimental production of neglect in monkeys. Brain 81, $341-347,1958$. 